\title{
Making Financial Management Process-Based and Professional
}

Finance must be process-based and professional; otherwise, it will incur high costs for the company. We need to standardize and streamline routine matters through processes and professional work. This will help reduce our management and operating costs.

At Huawei, Finance is positioned to be a global team that provides services, management, and oversight. To align with this positioning, Finance must develop as a professional global team that has solid integrity, dares to shoulder responsibilities, and sticks to principles. To better serve and manage business, financial managers must first understand business. We need to build a stronger PFC team. Project finance is the best place for financial personnel to hone their skills. Being involved in a small project from beginning to end can help financial personnel better understand finance and business, and get prepared for becoming CFOs.

Progress in finance is the basis for all management advances. Without robust financial management or reliable oversight, it will be impossible for a company to delegate authority to field offices; nor will field offices be able to call for support directly. In the end, the HQ will become increasingly bureaucratic and bloated. Such a company will not be able to survive and thrive over the long term. Huawei always remains customer-centric, focuses on value creation, continues to streamline management, and works hard to reduce period expenses.

This chapter discusses how Huawei builds a professional financial team.

(C) The Author(s) 2019

W. Huang, Built on Value, https://doi.org/10.1007/978-981-13-7507-1_17 


\subsection{Financial Personnel Should Understand Business and Business Personnel Should Understand FinANCE}

\subsubsection{Financial Personnel Can Help Business Grow Only by Understanding Business}

After you have mastered many modern tools and gained a deeper understanding of the business and people you serve, you can help improve efficiency. In that case, there will be hope for the company. You need to better understand the business and people you serve, and also customer needs. If you really understand the needs of your front-end customers, you will get promoted. (Ren Zhengfei: Speech at a Meeting with the IFS Project Team and Staff from Finance, Huawei Executive Office Speech No. [2009] 004)

I think staff at shared services centers need to be familiar with the business they serve. Otherwise, these shared service centers will become bureaucratic. If our financial personnel know nothing about business, they will not be able to communicate with field employees. Our financial personnel must step up efforts to upskill themselves and understand business as quickly as possible. I encourage those working in the shared services centers to become familiar with business. Otherwise, how can you possibly improve yourselves and do well in finance? The shared services centers are doomed to fail if they are composed only of financial experts who know nothing about business. (Ren Zhengfei: Speech at a Meeting with the IFS Project Team and Staff from Finance, Huawei Executive Office Speech No. [2009] 004)

CFOs should know how to make presentations on data and how to tell the stories behind the data. They need to analyze data to identify the patterns in business operations, and to develop methods to optimize business operations. This is how they can truly become business partners and help business grow. (Ren Zhengfei: Quickly Building Our CFO Team to Support IFS Deployment, Huawei Executive Office Speech No. [2009] 023)

Our financial team must be closely integrated with our business team. Business personnel must master financial knowledge, and financial personnel must acquire business knowledge. Financial personnel must have a clear and comprehensive idea of both finance and business, as this is the only way for them to effectively support project financial management. (Ren Zhengfei: Speech at a Work Report by the IFS-PTP Project Team, 2010) 
In recent years, we have constantly required our financial personnel to get closer to business and be deeply involved in projects. This is because we expect you to be more than bookkeepers. We hope you can truly understand the nature of our business and effectively support our business management. You may set on the right track only when you truly understand business. It is not an underestimation of your capabilities; rather it is our expectations of you. (Ren Zhengfei: Speech at a Meeting with Financial Staff, Huawei Executive Office Speech No. [2011] 032)

Huawei expects its CFOs to be result-oriented and work with business departments to sustainably produce maximum output with minimum input. (Ren Zhengfei: Speech at a Meeting with Financial Managers, Huawei Executive Office Speech No. [2012] 029)

Finance must deploy the right people to the right positions to ensure effective financial management and oversight. They should also ensure our talent and business structures are appropriate. (Ren Zhengfei: Speech at the Work Report by Finance, Huawei Executive Office Speech No. [2013] 234)

\subsubsection{Managers Are Also About Managing Finance}

In recent years, we have hired and transferred many business or financial personnel to managerial positions in Finance. If these people continue to know only about their own domain, either business or finance, they can no longer serve as managers. That's why this transformation project involves both our financial and business personnel. Financial personnel, either managers or employees, must understand accounting principles and know how to do specific financial work. These personnel also need to understand business. Otherwise, they are unable to better serve the company. We must realize that financial and business personnel must help and learn from each other. These two are not opposites, despite having some conflicting elements. Instead, they are an organic whole. (Ren Zhengfei: Minutes of a Meeting on Financial Transformation Projects, 2004)

$\mathrm{M}$ is for manager, and $\mathrm{M}$ is for money. If a manager doesn't understand how money flows in a business, then they can't possibly be an effective manager. (Ren Zhengfei: Speech at the Annual Meeting of the Chinese Market Finance Department, Huawei Executive Office Speech No. [2006] 002)

We will focus on profits during our performance appraisals. Representative office managers should understand management, finance, and operations. They should also continuously improve internal management and reduce operating costs. We aim to establish a management model under which 
business plays a leading role and finance plays an oversight role at account departments and representative offices. (Ren Zhengfei: Speech at the Report by the BT Account Department and the UK Representative Office, Huawei Executive Office Speech No. [2007] 015)

We live in an age of professional managers; the age of founders and heroes has passed. If we don't adapt to this trend, we will fall behind the times. During the transitional process, we need to work together closely as a team and cooperate with one another to achieve synergy. We must remember that nobody is good at everything. Those who never seek help are inefficient, and those who seek only individual success are destined to fail. (Ren Zhengfei: Timely, Accurate, High Quality, and Low Cost Delivery Calls for Professional Process-compliant CFOs-Minutes of a Meeting with Trainees of the CFO Session of the Reserve Pool, Huawei Executive Office Speech No. [2009] 021)

Business managers do not qualify as managers if they only have business knowledge. They also need to have the most basic financial knowledge. To have a future, we need a lot of enterprising successors. Where does our future lie? It lies with financial personnel who understand business and business personnel who understand planning, budgeting, and accounting. (Ren Zhengfei: Minutes of the Meeting with Staff of the Romania Accounting SSC, Huawei Executive Office Speech No. [2011] 021)

Managers should become familiar with each other's domains. Financial managers should understand business, and business managers should understand finance. We will have well-organized mobility for managers across these two domains to facilitate knowledge transfers. Field teams with mixed knowledge and experience are better positioned to seize opportunities more efficiently, quickly, and confidently, to balance project wins with robust operations, and to make full use of the LTC and IFS processes that have been deployed. The closed-loop management mechanism will be used to improve how managers are appraised and selected. (Ren Zhengfei: Applying the Spirit of the Tortoise to Catch up with the Dragon Spacecraft-Speech at Huawei Annual Management Conference 2013, Huawei Executive Office Speech No. [2013] 255)

Employees in all fields should rotate through R\&D, Sales, Finance, GTS, and other functions. Financial personnel must understand business. It is not enough for them to just passively read code. They need to take the initiative. Otherwise, they won't be able to become senior executives. Senior executives should have financial knowledge. Which of our senior executives don't understand finance? Apart from some Fellows and 
technical experts, who should delve deeper into their specific domains, the majority of our employees should rotate to improve their integrated capabilities. Our company now enjoys good business performance, so we will allow the Strategic Reserve to consume some profits. This will lay a solid foundation for the company's sustainable development. (Ren Zhengfei: There Will Not Always Be Flowers Along the Road Ahead-Speech at the HI Huawei Market Conference, Huawei Executive Office Speech No. [2016] 079)

\subsubsection{Financial Personnel Can Become Well-Rounded Managers Only by Knowing How to Manage Projects}

I think the most important task for financial personnel is to learn and gain experience in project financial management. Only those who know how to manage projects can become well-rounded managers. (Ren Zhengfei: Minutes of the Meeting with Staff of the Romania Accounting SSC, Huawei Executive Office Speech No. [2011] 021)

I think project finance needs to perform effective accounting and ensure that projects generate reasonable profits. Foxconn has standardized production processes, so their people do not need to have very sophisticated skillsets. However, our projects are very complicated, and we expect all of our employees to be deeply involved in project operations. You are more than just data collectors. You must be deeply involved in business. Only by doing this can you provide valuable suggestions. (Ren Zhengfei: Minutes of the Meeting with Staff of the Romania Accounting SSC, Huawei Executive Office Speech No. [2011] 021)

I don't think CFOs need the same level of accounting knowledge as accountants. If accountants knew as much about business as CFOs, they might also become CFOs. However, it is much more difficult for them to gain business knowledge, than it is for you to acquire accounting knowledge. So this year, I hope we can select 20 to 30 CFOs from employees at our regional offices and key account departments. I hope that our project teams can effectively manage planning, budgeting, and accounting. However, our financial personnel haven't developed the required capabilities yet. We can't even select CFOs in our regional offices. We hope you can take the initiative, make your voice heard, and help the company establish a financial management system. (Ren Zhengfei: Remarks at a Meeting with Senior Managers at a Project Management Summit, Huawei Executive Office Speech No. [2009] 007) 
We need to develop a stronger PFC team. In the future, our project financial team should include members from both business and finance departments. In particular, we will select some employees who have more than three years of engineering and technical experience and are also familiar with business, as well as some employees from Finance who are very familiar with business. We will train them quickly and send them to the field to enhance the roles of PFCs and business finance controllers (BFCs) within account departments. Project CFOs should also be selected from the project financial team. In the future, CFOs of representative offices or regional offices who are not familiar with finance or business should make up for their lack of knowledge. If they fail to do so, they can no longer hold managerial positions. (Ren Zhengfei: Integrating Project Estimation, Budgeting, Accounting, and Final Accounting to Support Project Operations-Speech at a Briefing on the IFS Project, Huawei Executive Office Speech No. [2010] 007)

Project finance is the best place for financial personnel to hone their skills. Being involved in a small project from beginning to end can help financial personnel better understand finance and business, and get prepared for becoming CFOs. (Ren Zhengfei: Speech at a Meeting with Financial Staff, Huawei Executive Office Speech No. [2011] 032)

Scientific management requires the support of Finance. Budgeting and final accounting are still our weak links. We should prioritize the development and sufficient deployment of PFCs. We can consider rotations between financial managers and business managers, in order to develop a team of managers and experts with integrated management capabilities. (Ren Zhengfei: Minutes of a Briefing on the Progress of the Project for Changing Function-centered Operations into Project-centered Operations, EMT Meeting Minutes No. [2014] 019)

We should deploy PFCs to effectively manage project delivery and reap the benefits of business management. Our project management is not yet very effective. In our early years, we knew nothing about delivery. Later on, after we understood delivery, we began to deliver as much as we could, and didn't care whether we made money or not. Today, we should continue to learn about delivery and also pay attention to delivery results. This calls for more PFCs. (Ren Zhengfei: Speech at a Meeting with Employees of the Central Asia \& Caucasia Region, Huawei Executive Office Speech No. [2016] 063)

PFCs must understand business to better manage projects. To become better PFCs in the future, new graduates should visit sites with engineers 
and see how equipment is installed. These graduates can use stopwatches to measure the time required and then calculate how much they earn each second. Then they can calculate how much we need to pay if an "express delivery man" does the same. This will show the benefits we can reap from business improvement. As our delivery becomes more standardized, we will become more open, and our software commissioning will become standardized. The first thing that a PFC needs to do is to go to the field and learn about business. This is the only way for us to achieve the threeprocedure loop - application, review, and approval. Otherwise, PFCs will be like "air force pilots" flying high in the air. If we don't give them the support and "fuel" they need, then they will fall to the ground. (Ren Zhengfei: Speech at a Meeting with Employees of the Central Asia \& Caucasia Region, Huawei Executive Office Speech No. [2016] 063)

\subsubsection{Developing a Mixed Financial Team}

Why do we transfer managers from business departments to Finance? The purpose is to help Finance get deeply involved in business, and change the way they think and work. Finance was widely known to be simple but stubborn. Managers had been working hard, but now they need to start working smarter. By adding some "sand", we aim to make you strong like concrete, rather than just replacing you with another manager. Those who want to transfer to Finance need to pass accounting exams. For middle managers, job rotations are conducive to their career development and comply with our zigzag development program. (Ren Zhengfei: Speech at a Meeting with Financial Staff, Huawei Executive Office Speech No. [2011] 032)

We need to build a diverse CFO resource pool that includes both financial and business personnel. We should not be too rigid or dogmatic when selecting CFOs. Rather, we should flexibly apply performance ratings, giving full consideration to the macro environment and the maturity of the markets in which CFOs are working. (Ren Zhengfei: Speech at the Work Report on Criteria for CFOs and the Mechanism for Their Development, Huawei Executive Office Speech No. [2011] 038)

We need to transfer some employees from other departments to Finance in order to build a stronger and more diverse financial team. This is like making concrete from pebbles, sand, and cement to make it more solid. We also need to recruit more talent from outside the company. However, Finance must not simply focus on vacancies; otherwise, those who are 
incompetent may never be removed from their positions. (Ren Zhengfei: Speech at the EMT ST Meeting, 2011)

Excellent financial managers can be transferred to business departments. This can provide them with more growth opportunities and drive integration between the financial and business teams. Excellent country CFOs can become general managers. Excellent project financial personnel can become project managers. This expansion of their career paths will exert a positive impact on business management. (Ren Zhengfei: Speech at the Work Report by Finance, Huawei Executive Office Speech No. [2013] 234)

We are rotating managers on a large scale through the JCR, placing managers in new positions, and adjusting our approaches and resources. We also aim to deploy our managers around the world. We believe that we will achieve these goals within the next three to five years. In the future, we will select some individuals from project finance and appoint them as project directors. Then, we will select some business personnel to do financial work for projects. Through such an exchange, we will be able to develop the managerial candidates that we want. If senior managers do not read or study corporate documents, they may be replaced by younger managers. (Ren Zhengfei: Growing from a Soldier to a General Within Three Years, Huawei Executive Office Speech No. [2014] 031)

\subsection{Building a Process-Based, Professional Financial Management System}

\subsubsection{Reducing Costs Through Process-Based and Professional Financial Management}

Our administrative management system used to be very disorganized. Although the impact of functional departments is weakening, it's still not practical to implement a process-based management system. Our upstream and downstream processes are not yet effectively integrated, and our process-based management system still needs to be optimized. In terms of organizational behavior, we have yet to achieve repeatable, predictable, and continuously reliable results in our operations. (Ren Zhengfei: Digging In, Widening Out-Speech at the Commendation Meeting of the Operations and Delivery Division, Huawei Executive Office Speech No. [2009] 009)

Finance must be process-based and professional; otherwise, it will incur high costs for the company. $\mathrm{CFO}$ is a universal term known internationally and we do not have a specific interpretation for this term. Our CFOs have 
the same job responsibilities as those defined in the industry. We need to standardize many aspects of our business through processes and professional work. This can reduce our management and operating costs. (Ren Zhengfei: Timely, Accurate, High Quality, and Low Cost Delivery Calls for Professional Process-compliant CFOs-Minutes of a Meeting with Trainees of the CFO Session of the Reserve Pool, Huawei Executive Office Speech No. [2009] 021)

In the industrial age, a military's effectiveness was measured by its ability to quickly assemble large forces and maintain maximum strength. In the twenty-first century, the US military became worried about difficulties such as increasing complexity and uncertainty, as well as demand to take quick action and win quickly. To address these challenges, the US military proposed the "forward presence" strategy, which is still in place today. With this strategy, US forces are deployed in hotspots to continuously gain onsite and real-time intelligence, and perform combat exercises with live ammunition. If an order is issued, the US forces can respond quickly to deal with enemy forces. The relevant reinforcements can then be sent by central command, which enables the military to quickly and decisively win the battle. We are attempting a similar strategy by gradually establishing CFO organizations for our industry-specific teams, regional offices, functional departments, account departments, projects, and customer groups. With these organizations in place, we aim to maximize the value of our financial personnel in our field business. Doing so will enable them to accurately identify and respond to changes, and become true, reliable business partners. (Ren Zhengfei: Comments to Huawei Finance Doc. No. [2011] 018, Huawei Executive Office Speech No. [2011] 025)

I think our major processes should be streamlined, allowing things to be completed quickly. When it comes to our strategy, our approach is to review our data pipes and remove any unnecessary parts to make the pipes transparent and ensure data flows through them quickly. We developed the pipe management system into a simple, clear, and transparent operating system. We then removed functionality from pipes and converted them into modules. This allows us to add them back to the pipes as needed. We should adopt the same approach with our major processes. I think our major processes are now burdened with heavy oversight tasks, leaving too many checkpoints throughout our major processes. This has made these processes very ineffective. In my opinion, these checkpoints should be set in our sub-processes, rather than major processes. (Ren Zhengfei: Speech and Comments at the Strategy Retreat of the Business 
Process \& IT Management Department, Huawei Executive Office Speech No. [2012] 026)

When our major processes are clean and transparent, we can streamline our major sub-processes. After all unnecessary functions are removed, our sub-processes will also become open and flexible. (Ren Zhengfei: Speech and Comments at the Strategy Retreat of the Business Process \& IT Management Department, Huawei Executive Office Speech No. [2012] 026)

More flexibility should be allowed in our back-end processes. For example, if our command center is located in Shenzhen, and it gives an order requiring all employees to wear a T-shirt, our colleagues working in the Arctic would freeze to death. Why does this happen? Because we are being too rigid and dogmatic and not allowing flexibility in field offices. So we now emphasize that back-end processes should be more flexible. (Ren Zhengfei: Speech and Comments at the Strategy Retreat of the Business Process \& IT Management Department, Huawei Executive Office Speech No. [2012] 026)

\subsubsection{Building a Professional Financial Team That Has Solid Integrity, Dares to Shoulder Responsibilities, and Sticks to Principles}

Our company will face great opportunities and challenges in the coming years. Finance must provide effective support. Finance needs to build a financial system more rapidly and improve its ability to provide services and make professional decisions. This is the only way for Finance to more effectively support the company's business development. Finance needs to position itself as a global team that provides services, management, and oversight. To align with this positioning, Finance must develop as a professional global team that has solid integrity, dares to shoulder responsibilities, and sticks to principles. (Ren Zhengfei: Building a Professional Financial Team That Has Solid Integrity, Dares to Shoulder Responsibilities, and Sticks to Principles, Huawei Executive Office Speech No. [2006] 038)

What is professionalism? It is doing the same thing under the same conditions, but at a lower cost. (Ren Zhengfei: Digging In, Widening Out-Speech at the Commendation Meeting of the Operations and Delivery Division, Huawei Executive Office Speech No. [2009] 009) 


\subsection{Progress in Finance Is the Basis for All Management Advances}

\subsubsection{Financial Transformation Is Not Limited to the Finance System, But a Company-Wide Effort}

We need a global financial team that is well beyond our HQ and manages all finance-related matters around the world. We are going to establish the position of regional financial management director. They will not be accounting directors, commercial managers, tax managers, or market finance managers. Instead, they will be commissioners assigned by Finance, International Marketing, and the company to regions. They should have a clear idea of accounting, regulations, revenue, and tax systems. (Ren Zhengfei: Speech at the Third Quarter Meeting Regarding Marketing in China, 2004)

Progress in finance is the basis for all management advances. The good news is that Finance has no longer been a drag on our business in the past few years. Without robust financial management or reliable oversight, it would be impossible for us to delegate authority to field offices; nor could field offices call for support directly. The result could be that the HQ becomes bureaucratic and bloated. If that happens, how can we survive and thrive? We must unwaveringly support the IFS ${ }^{1}$ transformation program. We need to build a stronger financial team. Our financial personnel need to upskill themselves and remain responsible, dedicated, integrated with business, and growth-oriented. They also need to better serve business, support business development, and manage planning, budgeting, and accounting from end to end. Only those who dare to make a difference can secure a place in the company. Departments can have growth opportunities only when they create value throughout the process. (Ren Zhengfei: The Market Economy Is Best for Competition; Economic Globalization Is Inevitable-Speech at the Commendation Meeting of Finance, Huawei Executive Office Speech No. [2009] 005)

We are now developing a process-based and professional management system. It is time for us to begin building a CFO management system. We expect that CFOs, once they come on board, will help cut down on

${ }^{1}$ IFS: Integrated Financial Services. This is Huawei's transformation program in the financial domain. It supports and oversees Huawei's end-to-end business processes from R\&D to marketing \& sales, supply chain, and delivery. 
waste and costs while maintaining rapid business growth. They will also help avoid partial optimization that can cause damage to the overall situation. We should always keep the big picture in mind. (Ren Zhengfei: Timely, Accurate, High Quality, and Low Cost Delivery Calls for Professional Process-compliant CFOs-Minutes of a Meeting with Trainees of the CFO Session of the Reserve Pool, Huawei Executive Office Speech No. [2009] 021)

The top priority for CFOs is to establish and implement financial processes that effectively support the operations of business processes. Both CFOs and CEOs need to properly understand and master company operations rules, and work together to help the company succeed and achieve sustainable and profitable growth. CFOs and CEOs are in the same boat, with the same goals and the same overall direction. However, they assume different responsibilities. Without the support of CFOs, CEOs cannot move forward. CFOs are not supposed to oversee CEOs; CFOs are there to establish and implement financial processes in a process-compliant and professional manner. This is necessary to support the effective operations of business processes and achieve sustainable and profitable growth. That means positive profits, positive net cash flow, and efficiency improvement. (Ren Zhengfei: Timely, Accurate, High Quality, and Low Cost Delivery Calls for Professional Process-compliant CFOs-Minutes of a Meeting with Trainees of the CFO Session of the Reserve Pool, Huawei Executive Office Speech No. [2009] 021)

What is the key to integrating the LTC, PTP, and OTC processes? It's the involvement of financial personnel in business, who are supposed to act like the glue that binds all people together. In the end, all processes will be integrated. (Ren Zhengfei: Speech at a Work Report by the IFS-PTP Project Team, 2010)

Over the past two decades, Finance has focused on developing vertical functional modules. This has helped build the right systems and processes. However, it has failed to provide effective, integrated management and strong support. Therefore, we need to further clarify the responsibilities and improve the capabilities of CFOs at representative offices and on projects. The aim is to improve the integrated management capabilities of financial organizations. (Ren Zhengfei: Speech at the Work Report on Criteria for CFOs and the Mechanism for Their Development, Huawei Executive Office Speech No. [2011] 038)

Financial transformation is about Huawei as a whole, rather than just the financial system. All senior management teams at Huawei must get 
involved in financial transformation. If a business department thinks it can transform successfully without any support, I would assume that this department can make profits without any expense. I do not think the director of this business department will go far. Similarly, Finance must not stay behind closed doors and think it is unnecessary to get business departments involved, give presentations to them, or listen to their opinions. (Ren Zhengfei: Financial Transformation Is About Huawei Rather Than Only the Finance System, Huawei Executive Office Speech No. [2007] 004)

We have made a lot of progress in our management. It's hard to imagine that a Chinese company could achieve such large revenue without encountering many problems. Over the past 28 years, we have put in place almost all the necessary processes, with our IT systems improving and management being streamlined. (Ren Zhengfei: There Will Not Always Be Flowers Along the Road Abead-Speech at the HI Huawei Market Conference, Huawei Executive Office Speech No. [2016] 079)

\subsubsection{There Will Not Always Be Flowers Along the Road Abead}

Our management must remain customer-centric and focus on value creation. We must gradually streamline our management and endeavor to reduce period expenses. If we make customers pay for product features they do not need, we will drive them away. Therefore, transformation must be measured by whether more crops can be harvested both in the short term and long term. (Ren Zhengfei: Our Transformation Goals Are to Harvest More Crops and Increase Soil Fertility-Speech at the 2015 Huawei Market Conference, Huawei Executive Office Speech No. [2015] 016)

Our financial management is already ahead of the pack within the industry. We are now able to check regional site inventories. The CIAG in central warehouses and sites has reached $99.89 \%$ and $98.17 \%$, respectively. A number of top experts and managers with successful field experience are continuing to develop and grow, but we should not rest on our laurels. (Ren Zhengfei: Be First to Know When Springtime Comes. Vow Not to Return Till We Reach Our Goals-Speech at an Oath-taking Rally for Reassigned Senior RerD Experts and Managers, Huawei Executive Office Speech No. [2016] 093)

Black swan events are emerging in great numbers around the world. There may be unexpected ups and downs, and we have yet to ensure strict 
internal and external compliance. We still need to step up our efforts to ensure more effective operations and ensure our financial systems are robust. (Ren Zhengfei: There Will Not Always Be Flowers Along the Road Ahead-Speech at the HI Huawei Market Conference, Huawei Executive Office Speech No. [2016] 079)

Open Access This chapter is licensed under the terms of the Creative Commons Attribution-NonCommercial-NoDerivatives 4.0 International License (http:// creativecommons.org/licenses/by-nc-nd/4.0/), which permits any noncommercial use, sharing, distribution and reproduction in any medium or format, as long as you give appropriate credit to the original author(s) and the source, provide a link to the Creative Commons licence and indicate if you modified the licensed material. You do not have permission under this license to share adapted material derived from this chapter or parts of it.

The images or other third party material in this chapter are included in the chapter's Creative Commons licence, unless indicated otherwise in a credit line to the material. If material is not included in the chapter's Creative Commons licence and your intended use is not permitted by statutory regulation or exceeds the permitted use, you will need to obtain permission directly from the copyright holder. 